\title{
Transforming Protein RhoA
}

National Cancer Institute

\section{Source}

National Cancer Institute. Transforming Protein RhoA. NCI Thesaurus. Code C17415.

Transforming protein RhoA (193 aa, $\sim 22 \mathrm{kDa}$ ) is encoded by the human RHOA gene. This protein is involved in the regulation of signal transduction pathways that control assembly of focal adhesions and actin stress fibers. 